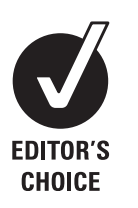
are published online only. To view these files please visit the journal online (http://jmg.bmj. com).

For numbered affiliations see end of article.

\section{Correspondence to}

Professor Nazneen Rahman,

Professor of Human Genetics,

Section of Cancer Genetics, The Institute of Cancer Research, 15 Cotswold Road, Sutton SM2 5NG, UK;

nazneen.rahman@icr.ac.uk

Received 4 August 2010 Revised 26 October 2010 Accepted 24 November 2010 Published Online First 25 January 2011

\title{
DICER1 syndrome: clarifying the diagnosis, clinical features and management implications of a pleiotropic tumour predisposition syndrome
}

Ingrid Slade, ${ }^{1}$ Chiara Bacchelli, ${ }^{1}$ Helen Davies, ${ }^{2}$ Anne Murray, ${ }^{1}$ Fatemeh Abbaszadeh, ${ }^{1}$ Sandra Hanks, ${ }^{1}$ Rita Barfoot, ${ }^{1}$ Amos Burke, ${ }^{3}$ Julia Chisholm, ${ }^{4}$ Martin Hewitt, ${ }^{5}$ Helen Jenkinson, ${ }^{6}$ Derek King, ${ }^{7}$ Bruce Morland, ${ }^{6}$ Barry Pizer, ${ }^{8}$ Katrina Prescott, ${ }^{9}$ Anand Saggar, ${ }^{10}$ Lucy Side, ${ }^{11}$ Heidi Traunecker, ${ }^{12}$ Sucheta Vaidya, ${ }^{13}$ Paul Ward, ${ }^{14}$ P Andrew Futreal, ${ }^{2}$ Gordan Vujanic, ${ }^{15}$ Andrew G Nicholson, ${ }^{16,17}$ Neil Sebire, ${ }^{18}$ Clare Turnbull, ${ }^{1}$ John R Priest, ${ }^{19}$ Kathryn Pritchard-Jones, ${ }^{13,20}$ Richard Houlston, ${ }^{1}$ Charles Stiller, ${ }^{21}$ Michael R Stratton, ${ }^{1,2}$ Jenny Douglas, ${ }^{1}$ Nazneen Rahman ${ }^{1}$

\section{ABSTRACT}

Background Constitutional DICER1 mutations were recently reported to cause familial pleuropulmonary blastoma (PPB).

Aim To investigate the contribution and phenotypic spectrum of constitutional and somatic DICER1 mutations to cancer.

Methods and results The authors sequenced DICER1 in constitutional DNA from 823 unrelated patients with a variety of tumours and in 781 cancer cell lines. Constitutional DICER1 mutations were identified in 19 families including 11/14 with PPB, 2/3 with cystic nephroma, 4/7 with ovarian Sertoli-Leydig-type tumours, 1/243 with Wilms tumour (this patient also had a Sertoli-Leydig tumour), 1/1 with intraocular medulloepithelioma (this patient also had PPB), 1/86 with medulloblastoma/infratentorial primitive neuroectodermal tumour, and 1/172 with germ cell tumour. The inheritance was investigated in 17 families. DICER1 mutations were identified in 25 relatives: 17 were unaffected, one mother had ovarian Sertoli-Leydig tumour, one half-sibling had cystic nephroma, and six relatives had non-toxic thyroid cysts/ goitre. Analysis of eight tumours from DICER1 mutation-positive patients showed universal retention of the wild-type allele. DICER1 truncating mutations were identified in 4/781 cancer cell lines; all were in microsatellite unstable lines and therefore unlikely to be driver mutations.

Conclusion Constitutional DICER1 haploinsufficiency predisposes to a broad range of tumours, making a substantial contribution to PPB, cystic nephroma and ovarian Sertoli-Leydig tumours, but a smaller contribution to other tumours. Most mutation carriers are unaffected, indicating that tumour risk is modest. The authors define the clinical contexts in which DICER1 mutation testing should be considered, the associated tumour risks, and the implications for at-risk individuals. They have termed this condition 'DICER1 syndrome'.

Accession numbers The cDNA Genbank accession number for the DICER1 sequence reported in this paper is NM 030621.2.

\section{INTRODUCTION}

DICER1 is an RNase endonuclease essential in the production of microRNAs (miRNAs), which are non-protein-coding small RNAs that are estimated to regulate the expression of over $30 \%$ of protein-coding genes at the post-transcriptional level. ${ }^{1}{ }^{2}$ miRNAs are transcribed as long precursors, known as pri-miRNAs, which are processed in the nucleus to produce pre-miRNAs. ${ }^{3}$ The pre-miRNAs are exported to the cytoplasm, where DICER1 processing generates a double-strand miRNA duplex. ${ }^{4}$ The duplex is unwound to generate the final miRNA, which interacts with mRNA to regulate gene expression, typically through translational repression or mRNA degradation. ${ }^{2} 56$

Over 900 human miRNAs are currently recognised. $^{7} 8$ These have been implicated in a wide range of biological processes including metabolism, morphogenesis, cell fate determination, cell proliferation and apoptosis. ${ }^{9} 10$ There is increasing evidence implicating dysregulation of miRNAs in several human diseases, including cancer. $^{11}{ }^{12}$ Widespread alteration of miRNA levels is seen in cancers, and miRNA profiles characteristic of cancer type and stage are increasingly recognised. ${ }^{12} 13$ Furthermore, global downregulation of miRNAs due to abrogation of miRNA processing has been shown to promote tumorigenesis. ${ }^{14}$

Recently, germline-inactivating DICER1 mutations were shown to cause familial pleuropulmonary blastoma (PPB, OMIM 601200), a rare malignant lung tumour, primarily affecting children before age $6 .{ }^{15}{ }^{16}$ By linkage analysis, Hill et al mapped a familial PPB gene to chromosome 14q. They considered DICER 1 to be a promising candidate and identified pathogenic mutations in 11 families. ${ }^{15}$ This important finding raises a number of questions. First, what is the contribution of DICER 1 mutations to non-familial, sporadic PPB? Mutations in some cancer-predisposition genes contribute appreciably to both familial and sporadic forms of disease, whereas for others the contribution to non-familial cases is small. Second, do constitutional DICER1 mutations predispose to tumours other than PPB? The International PPB Registry has collected information from over 200 
PPB families, and a variety of different tumours have been reported in PPB cases and/or their relatives ${ }^{17}{ }^{18}$ However, it is unknown which tumour types are genuinely associated with $\mathrm{PPB}$, which are related to DICER 1 mutations, and which reflect ascertainment. Third, do somatic DICER 1 mutations contribute to cancer? This is of particular interest as it has been proposed that somatic 14q loss, which has been reported in many cancers, may be targeted at DICER1. ${ }^{19-21}$

To address these questions, we have conducted exhaustive DICER1 sequencing, in $>1600$ patient samples, including constitutional DNAs from 823 individuals with a broad range of tumours, but particularly focusing on tumours that have been proposed to be associated with PPB (http://www.ppbregistry.

Table 1 Tumours in individuals screened for constitutional DICER1 mutations

\begin{tabular}{|c|c|c|}
\hline Tumour type & $\begin{array}{l}\text { No of } \\
\text { cases }\end{array}$ & $\begin{array}{l}\text { No with DICER1 } \\
\text { mutation }\end{array}$ \\
\hline \multicolumn{3}{|l|}{ Lung tumours } \\
\hline Pleuropulmonary blastoma & 14 & 11 \\
\hline Congenital lung cyst & 1 & \\
\hline \multicolumn{3}{|l|}{ Sex cord stromal tumours } \\
\hline Testicular Sertoli-Leydig/Sertoli/Leydig tumour & 11 & \\
\hline Ovarian Sertoli-Leydig tumour & 6 & 3 \\
\hline Ovarian granulosa cell tumour & 6 & \\
\hline Gonadal stromal cell tumour unclassified & 5 & \\
\hline Mixed stromal cell tumour & 1 & \\
\hline Stromal sex cord tumour unclassified & 1 & 1 \\
\hline \multicolumn{3}{|l|}{ Renal tumours } \\
\hline Wilms tumour & 243 & $1^{*}$ \\
\hline Cystic nephroma & 3 & 2 \\
\hline Clear cell sarcoma & 3 & \\
\hline \multicolumn{3}{|l|}{ Central nervous system tumours } \\
\hline Medulloblastoma/infratentorial PNET & 84 & 1 \\
\hline \multicolumn{3}{|l|}{ Eye tumours } \\
\hline Medulloepithelioma (dictyoma) & 1 & $1 \dagger$ \\
\hline \multicolumn{3}{|l|}{ Germ cell tumours } \\
\hline Seminoma & 71 & 1 \\
\hline Non-seminoma (testis) & 52 & \\
\hline Mixed testicular cancer & 14 & \\
\hline Embryonal carcinoma & 13 & \\
\hline Testicular cancer unspecified & 12 & \\
\hline Teratoma & 10 & \\
\hline Dysgerminoma/germinoma & 8 & \\
\hline Yolk sac tumour & 4 & \\
\hline Gonadoblastoma & 1 & \\
\hline Neuroblastoma & 73 & \\
\hline \multicolumn{3}{|l|}{ Thyroid carcinoma } \\
\hline Papillary thyroid carcinoma & 51 & \\
\hline Follicular thyroid carcinoma & 18 & \\
\hline Thyroid cancer unspecified & 15 & \\
\hline Anaplastic thyroid carcinoma & 4 & \\
\hline \multicolumn{3}{|l|}{ Soft tissue and other extraosseous sarcomas } \\
\hline Rhabdomyosarcoma & 19 & \\
\hline Fibrosarcoma & 7 & \\
\hline Other soft tissue sarcomas & 49 & \\
\hline \multicolumn{3}{|l|}{ Malignant bone tumours } \\
\hline Ewing sarcoma & 8 & \\
\hline Osteosarcoma & 7 & \\
\hline Chondrosarcoma & 4 & \\
\hline \multicolumn{3}{|l|}{ Hepatic tumours } \\
\hline Hepatoblastoma & 2 & \\
\hline Hepatocellular carcinoma & 2 & \\
\hline
\end{tabular}

*This patient also had ovarian Sertoli-Leydig cell tumour.

†This patient also had pleuropulmonary blastoma.

PNET, primitive neuroectodermal tumour.
org/pdf/Doc_D.pdf) (table 1). We also sequenced DICER1 in DNA from 781 cancer cell lines to assess the impact of somatic DICER 1 mutation on cancer development (online supplementary table 1).

\section{METHODS}

\section{Samples}

Constitutional DNA was extracted from EDTA venous blood samples and collected through the Factors Associated with Childhood Tumours (FACT) Study, the Royal Marsden Hospital cancer collections, and the Institute of Cancer Research UK-wide testicular germ cell tumour collections, all of which have been approved by an appropriate ethics board. All samples were obtained with full informed consent. The research was undertaken as part of the FACT Study, which was approved by the London Multicentre Research Ethics Committee (05/MRE02/17). The FACT Study aims to identify genetic factors that predispose to the development of childhood tumours (http:// www.icr.ac.uk/fact). The National Registry of Childhood Tumours was used to identify the total number (indicated in parentheses) of cases nationally for PPB (20, five of whom were deceased), cystic nephroma (15, none deceased) and SertoliLeydig cell tumours (seven, none deceased) that had been registered since its inception in 1962. The clinicians were contacted to request that they recruit these patients to the FACT Study. In addition, a small minority of patients referred to our clinical genetics service with these tumours were recruited directly. Tumour DNA from DICER1 mutation-positive paraffinembedded tissues was extracted using OIAamp DNA FFPE Tissue kit (Qiagen) according to the manufacturer's instructions. We analysed whole-genome amplified DNA from 781 cancer cell lines as part of the Cancer Genome Project, Cell Line Project (online supplementary table 1).

\section{DICER1 sequencing}

For analysis of the constitutional DNA, we designed PCR primers to amplify the 26 coding exons and intron-exon boundaries of DICER1 in a multiplex PCR (online supplementary table 2). Products were sequenced by capillary sequencing using the BigDye Terminator Cycle Sequencing Kit and an ABI3730 Genetic Analyser (Applied Biosystems, Foster City, California, USA). Sequences were analysed using Mutation Surveyor software V.3.20 (SoftGenetics). We only included samples in which at least $90 \%$ or more of the coding sequence was successfully screened in subsequent analyses. For the cancer cell lines, PCR primers that amplify $500 \mathrm{bp}$ PCR products encompassing the 26 coding DICER 1 exons and intron-exon boundaries were designed and sequenced as described above. Sequence traces were analysed using AutoCSA software, ${ }^{22}$ followed by manual inspection of putative variants. All putative variants were confirmed by bidirectional sequencing of a second independently amplified PCR product. Matched normal cell lines were available for 40 cell lines. The somatic status of variants identified in these 40 cell lines was determined by sequencing DNA from the corresponding normal. In the remaining cell lines, we assumed that cell line variants that were also identified in the constitutional DNA screen were not somatic. We evaluated the likely pathogenicity of sequence variants using Polyphen, SIFT and NNSplice software.

\section{RESULTS}

\section{Germline DICER1 mutation analysis}

We identified pathogenic mutations in 19/823 index individuals (table 2 and online supplementary figure 1). Seventeen 
Table 2 Probands and relatives with constitutional DICER1 mutations

\begin{tabular}{|c|c|c|c|}
\hline ID & Phenotype & $\begin{array}{l}\text { Age at } \\
\text { diagnosis } \\
\text { (years) }\end{array}$ & $\begin{array}{l}\text { Current } \\
\text { age } \\
\text { (years) }\end{array}$ \\
\hline \multicolumn{4}{|c|}{ Family 1 - c.4403_4406delCTCT } \\
\hline Proband & Pleuropulmonary blastoma & 1.5 & 5 \\
\hline Parent & None & & 40 \\
\hline Uncle & None & & 44 \\
\hline Grandparent & None & & 68 \\
\hline \multicolumn{4}{|c|}{ Family 2 - c.1716delT } \\
\hline Proband & Pleuropulmonary blastoma & 0.8 & 2 \\
\hline Parent & None & & 36 \\
\hline \multicolumn{4}{|c|}{ Family 3 - c.1196_1197dupAG } \\
\hline Proband & Pleuropulmonary blastoma & 4 & 5 \\
\hline Parent & None & & 30 \\
\hline Aunt & None & & 26 \\
\hline Grandparent & None & & 62 \\
\hline \multicolumn{4}{|c|}{ Family 4 - c.3505delT } \\
\hline Proband & Pleuropulmonary blastoma & 3 & 3 \\
\hline Sibling & None & & 12 \\
\hline Parent & None & & 36 \\
\hline \multicolumn{4}{|c|}{ Family 5 - c.1966C>T p.R656X } \\
\hline Proband & Pleuropulmonary blastoma & 7 & 12 \\
\hline Parent & None & & 52 \\
\hline \multicolumn{4}{|c|}{ Family 6 - c.2268_2271delTTTG } \\
\hline Proband & Pleuropulmonary blastoma & 0.9 & 1 \\
\hline Parent & None & & 38 \\
\hline \multicolumn{4}{|c|}{ Family 7 - c.3665delT } \\
\hline Proband & Pleuropulmonary blastoma* & 4.2 & died 5.2 \\
\hline Parent & None & & 36 \\
\hline \multicolumn{4}{|c|}{ Family 8 - c.3583_3584delGA } \\
\hline \multirow[t]{2}{*}{ Proband } & Pleuropulmonary blastoma & 1.3 & 7 \\
\hline & Intraocular medulloepithelioma & 6 & \\
\hline parent & None & & 29 \\
\hline \multicolumn{4}{|c|}{ Family $9-\mathrm{c} .2040+1 \mathrm{G}>\mathrm{C}$} \\
\hline Proband & Pleuropulmonary blastoma & 3 & 13 \\
\hline Parent & Thyroid cysts unclassified & 25 & 38 \\
\hline \multicolumn{4}{|c|}{ Family 10 - c.3726C>A p.Y1242X } \\
\hline Proband & Pleuropulmonary blastoma & 4 & 15 \\
\hline Parent & Thyroid cysts unclassified & 30 & 37 \\
\hline \multicolumn{4}{|c|}{ Family 11 - c.5465A>T p.D1822V† } \\
\hline Proband & Pleuropulmonary blastoma & 1.8 & 9 \\
\hline Parent & Thyroid cysts unclassified & 20 & 40 \\
\hline \multicolumn{4}{|c|}{ Family 12 - c.3288_3289insTTTC } \\
\hline Proband & Cystic nephroma & 1.5 & 11 \\
\hline Half-sibling & Cystic nephroma & 0.8 & 5 \\
\hline Parent & Multinodular colloid goitre & 25 & 39 \\
\hline \multicolumn{4}{|c|}{ Family 13 - c.328_338dupGTGTCAGCTGT } \\
\hline Proband & Cystic nephroma & 3 & 5 \\
\hline \multirow[t]{2}{*}{ Parent } & Multinodular colloid goitre & 20 & 35 \\
\hline & Thyroglossal duct cyst & 30 & \\
\hline Grandparent & Thyroid cysts unclassified & 7 & 66 \\
\hline Great-aunt & None & & 59 \\
\hline \multicolumn{4}{|c|}{ Family 14 - c.5122_5128delGGAGATG } \\
\hline \multirow[t]{2}{*}{ Proband } & Ovarian Sertoli-Leydig cell tumour L & 17 & 35 \\
\hline & Ovarian Sertoli-Leydig cell tumour R & 27 & \\
\hline Parent & Ovarian Sertoli-Leydig cell tumour R & 21 & 71 \\
\hline & Melanoma & 50 & \\
\hline & Endometrial cancer & 62 & \\
\hline & Breast cancer & 68 & \\
\hline Family $15-c .1$ & C>T_p.R656X & & \\
\hline Proband & Ovarian Sertoli-Leydig cell tumour R & 12 & 17 \\
\hline & Ovarian Sertoli-Leydig cell tumour L & 14 & \\
\hline Parent & None & & 50 \\
\hline
\end{tabular}

Table 2 Continued

\begin{tabular}{|c|c|c|c|}
\hline ID & Phenotype & $\begin{array}{l}\text { Age at } \\
\text { diagnosis } \\
\text { (years) }\end{array}$ & $\begin{array}{l}\text { Current } \\
\text { age } \\
\text { (years) }\end{array}$ \\
\hline \multicolumn{4}{|c|}{ Family 16 - c.3793delA } \\
\hline Proband & Ovarian sex cord stromal tumour $\mathrm{R}$ & 6 & 9 \\
\hline Parent & None & & 29 \\
\hline \multicolumn{4}{|c|}{ Family 17 - c.2988-2_2988-1delAGinsCT } \\
\hline \multirow[t]{4}{*}{ Proband } & Wilms tumour & 8 & 15 \\
\hline & $\begin{array}{l}\text { Multinodular thyroid goitre } \\
\text { unclassified }\end{array}$ & 9 & \\
\hline & Ovarian Sertoli-Leydig cell tumour $\mathrm{R}$ & 12 & \\
\hline & Ovarian Sertoli-Leydig cell tumour L & 12 & \\
\hline Parent & None & & 40 \\
\hline \multicolumn{4}{|c|}{ Family 18 - c.1153delC } \\
\hline Proband & Medulloblastoma/infratentorial PNET & 13 & 18 \\
\hline \multicolumn{4}{|c|}{ Family 19 - c. $4740 \mathrm{G}>\mathrm{T}$ p. $01580 \mathrm{H}$} \\
\hline Proband & Seminoma & 32 & 46 \\
\hline
\end{tabular}

*Individual deceased, no sample available.

†This family includes a sibling with neuroblastoma; no sample available.

mutations led to premature protein truncation as a result of frameshift, nonsense or consensus splice-site mutations. Two mutations are missense alterations, for which there is substantial evidence of pathogenicity. First, they are the only two missense alterations in the 3214 chromosomes screened that are predicted to be pathogenic by SIFT and Polyphen. Second, both target highly conserved residues in the RNase III domain. Third, they are in the vicinity of a missense variant identified by Hill et al, which resulted in a similar DICER1 histochemical profile to truncating mutations. ${ }^{15}$ We also identified several non-pathogenic variants including nine missense variants, 23 synonymous variants, and five intronic variants (online supplementary table 3).

\section{Pleuropulmonary blastoma}

We identified DICER 1 mutations in 10 individuals with PPB and in the mother of a child that had died from PPB but from whom no sample was available. One child developed an intraocular medulloepithelioma 4 years after $\mathrm{PPB}$. Three-generational pedigrees were available for most cases, and no relative had PPB. One sibling died from neuroblastoma; her DICER 1 status is not known, but a mutation was present in her mother. There were three children with PPB, in whom we did not identify a DICER 1 mutation.

\section{Cystic nephroma}

The most common reported association of PPB is cystic nephroma, ${ }^{17}$ a rare benign renal tumour that typically presents as a multicystic renal mass without solid nodules. It has a bimodal incidence with $50 \%$ occurring in children less than 4 years and $30 \%$ in the 5 th and 6 th decades. ${ }^{23}$ We had DNA from three unilateral childhood cases, and in two we identified truncating DICER1 mutations. One of the children had a half-sibling with cystic nephroma who also has the mutation. The child in the second DICER1 mutation-positive case was recently found to have a small lung cyst, which is being monitored but has not had histological evaluation.

Ovarian Sertoli-Leydig tumours

We analysed DNA from 30 individuals with sex cord tumours, of which six were ovarian Sertoli-Leydig tumours, which are sex cord tumours that exhibit testicular differentiation. ${ }^{24}$ The age range of diagnosis is $2-75$ years, but $\sim 75 \%$ present in the 
second or third decades. ${ }^{24}$ We identified truncating DICER 1 mutations in four individuals; three had young-onset bilateral ovarian Sertoli-Leydig tumours, and one had a unilateral ovarian sex cord tumour that could not be further classified because of necrosis. In one of the bilateral cases, Wilms tumour was previously present (see below). The mother of one patient had also developed a Sertoli-Leydig tumour at 21 years and carried the DICER 1 mutation. She has subsequently had melanoma at 50 years, endometrial cancer at 62 years, and breast cancer at 68 years.

\section{Wilms tumour}

Wilms tumour is an embryonal cancer of the kidney that affects $\sim 1$ in 10000 children, usually before the age of 6 years. ${ }^{25}{ }^{26} \mathrm{We}$ analysed DNA from 243 patients with Wilms tumour. We identified one truncating DICER 1 mutation, in a child who developed Wilms tumour of atypical histology at the unusually late age of 8 years. Four years after treatment the child developed bilateral ovarian Sertoli-Leydig cell tumours.

\section{Medulloblastoma/infratentorial primitive neuroectodermal tumour (PNET)}

Medulloblastoma is a PNET that arises in the posterior fossa. ${ }^{27}$ We analysed 84 childhood medulloblastoma/infratentorial PNET cases and identified one truncating mutation in a child of 13 years. No other information or samples were available.

\section{Seminoma}

We analysed DNA from 185 individuals with germ cell tumour, of which 128 had a family history of testicular cancer. We identified one missense DICER1 mutation, $\mathrm{Q} 1580 \mathrm{H}$. A maternal first cousin once removed of this proband developed testicular cancer at 27 years, but the proband's mother does not carry the DICER 1 mutation. It is not possible to conclusively establish whether this mutation is pathogenic on the available evidence.

\section{Intraocular medulloepithelioma}

Intraocular medulloepithelioma, also known as dictyoma, is a very rare embryonal tumour, usually originating in the ciliary body of the eye, which most commonly occurs during childhood. ${ }^{28}$ One child with PPB also developed a dictyoma and has a DICER1 mutation.

\section{Thyroid non-toxic goitres/cysts}

In the PPB Registry, thyroid cancers and thyroid hyperplasia are reported in both probands and relatives of PPB cases. We analysed DNA from 88 patients with thyroid cancer, but did not identify any mutations. However, one proband and six relatives of DICER1 mutation-positive individuals developed thyroid cysts/multinodular colloid goitre between the ages of 9 and 30 years. All were non-toxic, associated with normal thyroid function, and non-malignant. Thyroidectomy was required in four patients because of recurrent disease.

\section{Other tumours/cysts}

We did not identify mutations in any of the other tumour types as detailed in table 1 .

\section{Family studies in DICER1 mutation-positive individuals}

We had samples from both parents in 17 families in which a DICER1 mutation had been identified in an index individual. In each, the mutation had been inherited (table 2). We had grandparental samples for five families. In two families, the mutation was absent in the respective grandparents, indicating that the mutation had arisen de novo in the parent. In the other three families, the mutation was present in a grandparent.

We analysed DNA from 51 relatives, and we identified 25 relatives with DICER1 mutations. Of these, as described above, one mother had a Sertoli-Leydig tumour, one half-sibling had cystic nephroma, and six relatives had thyroid cysts/goitre. The remaining 17 individuals did not have clinical features or symptoms likely to be related to the DICER 1 mutation, one relative having muscular dystrophy and another Wegener's granulomatosis.

\section{Analysis of tumours from DICER1 mutation-positive individuals}

We obtained eight tumours from six DICER 1 mutation-positive individuals. This included three PPB, four Sertoli-Leydig tumours, and one cystic nephroma. We analysed each tumour for the relevant mutation. Each was heterozygous for the mutation-that is, the tumour showed a similar mutational profile to that in the blood and there was no loss of the wild-type allele in any tumour.

\section{DICER1 mutation analysis in cancer cell lines}

We screened 781 cancer cell lines (online supplementary table 1) for DICER 1 mutations. These represent an extensive crosssection of cancers, but do not include many of the cancers in which we identified germline DICER1 mutations. Two hundred and six of the cell lines have previously been shown to have loss of heterozygosity of $14 \mathrm{q}$ encompassing DICER 1 .

We identified four truncating mutations in the 781 cell lines, and these were in microsatellite unstable lines. We identified 22 non-synonymous variants that were either proven to be somatic or in which normal DNA was not available for evaluation. None were predicted to be deleterious (online supplementary table 4).

\section{DISCUSSION}

In 2009, germline DICER 1 mutations were identified in familial $\mathrm{PPB}$, adding to the list of rare familial cancer syndromes that have yielded critical evidence linking essential biological processes with cancer causation. ${ }^{15}$ In this study, we have expanded knowledge of the link between DICER 1 and cancer. First, we demonstrate that germline DICER1 mutations are the major cause of PPB. In the UK, 20 cases of PPB have been registered in the National Registry of Childhood Tumours over the last 35 years. We were able to include 14 in this study, none of which had a family history of PPB. We identified DICER 1 mutations in 11 of these cases. This represents one of the largest known contributions of germline mutations of a single gene to a specific tumour type. It is uncertain whether cryptic DICER 1 mutations account for any of the negative cases, whether mutations in another gene can also cause PPB, or whether the remaining cases are not due to germline predisposition genes. However, it is clear that germline DICER1 mutations are the major cause of both familial and non-familial PPB.

We have also demonstrated that DICER1 mutations cause a range of phenotypes; not all families include PPB, and a high proportion of mutation carriers are clinically well. In view of this, we suggest that 'DICER1 syndrome' is a preferable term to 'PPB familial tumour syndrome', which has previously sometimes been used. The range of different tumours that can occur in individuals with DICER 1 mutations is broad, and it is likely that more associated tumours will be identified as further mutation testing is undertaken. The contribution of DICER 1 mutations to different tumours is very variable. The major tumours that occur in DICER1 syndrome appear to be PPB, cystic nephroma and ovarian Sertoli-Leydig tumour. 
Figure 1 Different mechanisms of cancer predisposition resulting from germline mutations in tumour suppressor genes. (A) The classic twohit mechanism, exemplified by retinoblastoma, involves a germline/ constitutional mutation which constitutes the first hit and is present in every cell. A second mutation (hit) targeting the wild-type allele in a retinoblast has to occur for oncogenesis to proceed. (B)

Haploinsufficiency mechanism, exemplified by DICER1 syndrome. A germline/constitutional mutation predisposes to tumours. One or more additional events are required for oncogenesis to proceed, but does not appear to include inactivation of the wild-type DICER1 allele. mut, mutant; wt, wild-type.

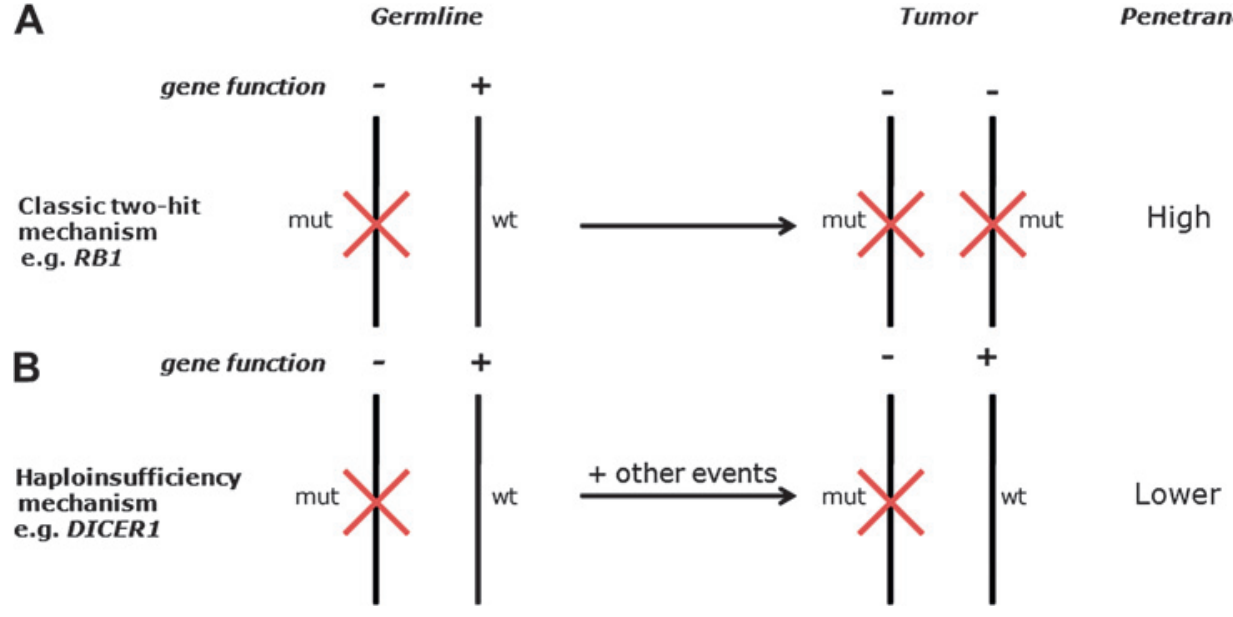

Evidence for this comes from our mutational data, our clinical and mutational investigation of relatives of mutation-positive probands, and from the spectrum of tumours that have been documented in relatives of PPB cases in the PPB Registry. ${ }^{17} 18$ The contribution of DICER 1 mutations to different tumours is also very variable. Although germline DICER1 mutations may contribute significantly to cystic nephroma, ovarian SertoliLeydig tumour and intraocular medulloepithelioma, they are unlikely to have a major impact on the incidence of Wilms tumour, medulloblastoma/infratentorial PNET or neuroblastoma.

In addition to tumours, DICER1 mutations also appear to confer a risk of thyroid cysts. One proband and six DICER 1 mutation-positive relatives developed thyroid cysts in childhood or young adulthood. Although histology results were only available for two cases, both were non-toxic multinodular colloid goitres. This is of particular interest, as the gene for familial non-toxic multinodular thyroid goitre has been previously shown to localise to $14 \mathrm{q} \cdot{ }^{29}$

The mutation analyses in cancer cell lines suggest that somatic DICER1 mutations do not make a substantial contribution to cancer. This is in contrast with recent reports hypothesising that the 14q hemizygosity observed in 206/761 cell lines is targeted at DICER $1 .{ }^{19-21}$ In the great majority of the cell lines, the $14 \mathrm{q}$ loss of heterozygosity extends over a very large area and includes many genes. If loss of DICER 1 were the main driver, one would expect that somatic DICER1 mutations would occur in at least some of the cell lines with normal 14q chromosomes. However, we only identified four truncating mutations, and these were in microsatellite unstable lines and therefore unlikely to be driver mutations. Thus the somatic mutational profile of DICER 1 appears to differ from that of other ubiquitously expressed, critically important genes, such as TP53 and RB1, which also predispose to rare childhood cancers when mutated in the germline.

The mechanism of DICER1 tumour predisposition also appears to differ from the majority of known cancer-predisposition genes and is likely to operate by a haploinsufficiency mechanism (figure 1). Our analysis of tumours showed no loss of the wild-type allele, and Hill et al showed retained DICER1 expression in tumour cells. ${ }^{15}$ Data from mice studies are also consistent with a haploinsufficiency model and indicate that, whereas monoallelic DICER1 inactivation promotes tumorigenesis, biallelic loss is inhibitory. ${ }^{20} 21$ Our data further suggest that, although inactivation of one DICER 1 allele is the initiating event in DICER1 syndrome, presumably because it leads to dysregulation of miRNA levels, other events must be required for cancer to occur. It is not known what these additional events are, or how many are required for oncogenesis to proceed. However, the low frequency of tumours in DICER 1 mutation carriers suggests that either more than one additional event is required and/or the likelihood of the event(s) occurring is small.

Our data demonstrate that the risk of tumours in DICER 1 mutation carriers is low, and most mutation carriers do not develop tumours. This modest penetrance and the variable phenotype of DICER 1 syndrome raise significant clinical challenges. We suggest that diagnostic DICER 1 testing should be considered in individuals with possible PPB, cystic nephroma, ovarian Sertoli-Leydig tumour or medulloepithelioma. The prevalence of mutations in these conditions may be considerable, and identification of a DICER 1 mutation can aid diagnosis and management, particularly for PPB, which can show significant clinical overlap with other types of lung cyst. ${ }^{18} 30$

The issue of surveillance in a pleiotropic condition of modest penetrance is also complex. To date, ad hoc, variable screening for PPB has been undertaken in individual families, often using lung CT, which can require an anaesthetic, involves radiation exposure, and is of unproven efficacy. ${ }^{31}$ Moreover, the natural history and appropriate management of such screen-detected lesions in a well child is unknown. In view of these considerations and the modest penetrance, we are currently operating an 'open-door' management policy with early investigation of potential

\section{Web resources}

The URLs for data presented herein are as follows:

- OMIM, http://www.ncbi.nlm.nih.gov/0mim/

- PPB Registry, http://www.ppbregistry.org/pdf/Doc_D.pdf

- Cancer Genome Project, Cell Line Project, http://www.sanger. ac.uk/genetics/CGP/CellLines/

- Polyphen, http://genetics.bwh.harvard.edu/pph/

- SIFT, http://blocks.fhcrc.org/sift/SIFT.html

- NNSplice, http://www.fruitfly.org/seq_tools/splice.html

- Cancer Genome Project, Catalogue of Somatic Mutations in Cancer, http://www.sanger.ac.uk/perl/genetics/CGP/cosmic 
tumour-related symptoms, but we are not undertaking routine surveillance in healthy mutation-positive individuals. This policy will be under continuous review, particularly over the next few years, when extensive expert discussions about the optimal management of DICER 1 mutation carriers are likely to occur.

In this study, we clarify the phenotypes associated with constitutional DICER1 mutations and propose that the condition should be called 'DICER 1 syndrome'. In the future, additional research will hopefully further clarify the clinical features, tumour risks, and optimal management of this condition and will illuminate the mechanisms by which DICER1 haploinsufficiency predisposes to human disease.

\section{Author affiliations}

${ }^{1}$ Section of Cancer Genetics, Institute of Cancer Research and Royal Marsden Hospital, Sutton, Surrey, UK

${ }^{2}$ The Wellcome Trust Sanger Institute, Hinxton, Cambridge, UK

${ }^{3}$ Pediatric Oncology, Addenbrooke's Hospital, Cambridge, UK

${ }^{4}$ Department of Pediatric Oncology, Great Ormond Street Hospital, London, UK

${ }^{5}$ Pediatric Oncology, Nottingham University Hospital, Nottingham, UK

${ }^{6}$ Pediatric Oncology, Birmingham Children's Hospital, Birmingham, UK

${ }^{7}$ Department of Haematology and Oncology, Royal Aberdeen Children's Hospital, Aberdeen, Scotland, UK

${ }^{8}$ Department of Pediatric Oncology, Alder Hey Children's Hospital, Liverpool, UK

${ }^{9}$ Department of Clinical Genetics, Chapel Allerton Hospital, Leeds, UK

${ }^{10}$ Department of Clinical Genetics, St George's Hospital, London, UK

${ }^{11}$ Department of Clinical Genetics, Great Ormond Street Hospital, London, UK

${ }^{12}$ Pediatric Oncology, Children's Hospital for Wales, Cardiff, UK

${ }^{13}$ Section of Pediatrics, Institute of Cancer Research and Royal Marsden Hospital,

Sutton, Surrey, UK

${ }^{14}$ Department of Pediatrics, Derriford Hospital, Plymouth, UK

${ }^{15}$ Department of Histopathology, School of Medicine, Cardiff University, Cardiff, UK

${ }^{16}$ Department of Histopathology, Royal Brompton Hospital, UK

${ }^{17}$ The National Heart and Lung Institute, Imperial College, London, UK

${ }^{18}$ Department of Histopathology and Pediatric Laboratory Medicine, Great Ormond

Street Hospital, London, UK

${ }^{19}$ International PPB Registry, Children's Hospitals and Clinics of Minnesota,

Minneapolis, USA

${ }^{20}$ Molecular Haematology and Cancer Biology, Institute of Child Health, London, UK

${ }^{21}$ Childhood Cancer Research Group, Department of Pediatrics, University of Oxford, Oxford, UK

Acknowledgements We thank the children and families involved in the research, and the physicians, nurses and pathologists who referred families and provided samples. We are grateful for assistance with recruitment and discussions with the International PPB Registry. We thank Katrina Tatton-Brown, Helen Hanson, Trevor Cole, Anita Bayne, Margaret Warren-Perry, Darshna Dudakia, Polly Gibbs, Jessie Bull and Anna Zachariou for assistance with recruitment. We thank Katrina Spanova, Bernadette Ebbs and Deborah Hughes for running the ABI sequencers. We thank Ann Strydom for assistance with the manuscript. The research was carried out as part of the Factors Associated with Childhood Tumours (FACT) Study, which is a UK Children's Cancer and Leukaemia Group (CCLG) study.

Funding The Childhood Cancer Research Group receives funding from the Department of Health and the Scottish Ministers. The views expressed in this publication are those of the authors and not necessarily those of the Department of Health and the Scottish Ministers. IS is supported by the Michael and Betty Kadoorie Cancer Genetics Research Programme. We acknowledge NHS funding to the NIHR Biomedical Research Centre. This work was supported by Cancer Research UK (grants C8620 A9024 and C8620 A8857) and the Institute of Cancer Research (UK).

\section{Competing interests None.}

Ethics approval This study was conducted with the approval of the NHS National Research Ethics Service.

Provenance and peer review Not commissioned; externally peer reviewed.

\section{REFERENCES}

1. Matsuda S, Ichigotani $Y$, Okuda T, Irimura T, Nakatsugawa S, Hamaguchi M Molecular cloning and characterization of a novel human gene (HERNA) which encodes a putative RNA-helicase. Biochim Biophys Acta 2000:1490:163-9.

2. Carthew RW. Gene regulation by microRNAs. Curr Opin Genet Dev 2006:16:203-8.
3. Gregory RI, Yan KP, Amuthan G, Chendrimada T, Doratotaj B, Cooch N, Shiekhattar R. The Microprocessor complex mediates the genesis of microRNAs. Nature 2004;432:235-40.

4. Bernstein E, Caudy AA, Hammond SM, Hannon GJ. Role for a bidentate ribonuclease in the initiation step of RNA interference. Nature 2001:409:363-6.

5. Hammond SM, Boettcher S, Caudy AA, Kobayashi R, Hannon GJ. Argonaute2, a link between genetic and biochemical analyses of RNAi. Science 2001;293:1146-50

6. Bartel DP. MicroRNAs: target recognition and regulatory functions. Cell 2009;136:215-33.

7. Backes C, Meese E, Lenhof HP, Keller A. A dictionary on microRNAs and their putative target pathways. Nucleic Acids Res 2010:38:4476-86.

8. Griffiths-Jones S, Saini HK, van Dongen S, Enright AJ. miRBase: tools for microRNA genomics. Nucleic Acids Res 2008;36:D154-8.

9. Stadler BM, Ruohola-Baker H. Small RNAs: keeping stem cells in line. Cell 2008;132:563-6

10. Stefani G, Slack FJ. Small non-coding RNAs in animal development. Nat Rev Mol Cell Biol 2008;9:219-30.

11. Zhang B, Pan $X$, Cobb GP, Anderson TA. microRNAs as oncogenes and tumor suppressors. Dev Biol 2007:302:1-12.

12. Lee YS, Dutta A. MicroRNAs in cancer. Annu Rev Pathol 2009;4:199-227.

13. Croce CM. Causes and consequences of microRNA dysregulation in cancer. Nat Rev Genet 2009:10:704-14.

14. Kumar MS, Lu J, Mercer KL, Golub TR, Jacks T. Impaired microRNA processing enhances cellular transformation and tumorigenesis. Nat Genet 2007:39:673-7.

15. Hill DA, Ivanovich J, Priest JR, Gurnett CA, Dehner LP, Desruisseau D, Jarzembowski JA Wikenheiser-Brokamp KA, Suarez BK. Whelan AJ, Williams G, Bracamontes D, Messinger Y, Goodfellow PJ. DICER1 mutations in familial pleuropulmonary blastoma. Science 2009;325:965

16. Priest JR, Watterson J, Strong L, Huff V, Woods WG, Byrd RL, Friend SH, Newsham I, Amylon MD, Pappo A, Mahoney DH, Langston C, Heyn R, Kohut G, Freyer DR, Bostrom B, Richardson MS, Barredo J, Dehner LP. Pleuropulmonary blastoma: a marker for familial disease. J Pediatr 1996:128:220-4.

17. Boman F, Hill DA, Williams GM, Chauvenet A, Fournet JC, Soglio DB, Messinger $Y$ Priest JR. Familial association of pleuropulmonary blastoma with cystic nephroma and other renal tumors: a report from the International Pleuropulmonary Blastoma Registry. J Pediatr 2006;149:850-4.

18. Priest JR, Williams GM, Hill DA, Dehner LP, Jaffe A. Pulmonary cysts in early childhood and the risk of malignancy. Pediatr Pulmonol 2009;44:14-30.

19. Forbes SA, Tang G, Bindal N, Bamford S, Dawson E, Cole C, Kok CY, Jia M, Ewing R Menzies A, Teague JW, Stratton MR, Futreal PA. COSMIC (the Catalogue of Somatic Mutations in Cancer): a resource to investigate acquired mutations in human cancer Nucleic Acids Res 2010;38:D652-7.

20. Kumar MS, Pester RE, Chen CY, Lane K, Chin C, Lu J, Kirsch DG, Golub TR, Jacks T. Dicer1 functions as a haploinsufficient tumor suppressor. Genes Dev 2009:23:2700-4

21. Lambertz I, Nittner D, Mestdagh P, Denecker G, Vandesompele J, Dyer MA, Marine JC Monoallelic but not biallelic loss of Dicer1 promotes tumorigenesis in vivo. Cell Death Differ 2010:17:633-41.

22. Dicks E, Teague JW, Stephens P, Raine K, Yates A, Mattocks C, Tarpey P, Butler A Menzies A, Richardson D, Jenkinson A, Davies H, Edkins S, Forbes S, Gray K, Greenman C, Shepherd R, Stratton MR, Futreal PA, Wooster R. AutoCSA, an algorithm for high throughput DNA sequence variant detection in cancer genomes. Bioinformatics 2007:23:1689-91.

23. Stamatiou K, Polizois K, Kollaitis G, Dahanis S, Zafeiropoulos G, Leventis C, Lambou T. Cystic nephroma: a case report and review of the literature. Cases $J$ 2008;1:267.

24. Young RH, Scully RE. Ovarian Sertoli-Leydig cell tumors. A clinicopathological analysis of 207 cases. Am J Surg Pathol 1985;9:543-69.

25. Stiller CA. Parkin DM. International variations in the incidence of childhood renal tumours. Br J Cancer 1990;62:1026-30.

26. Breslow N, Beckwith JB, Ciol M, Sharples K. Age distribution of Wilms' tumor report from the National Wilms' Tumor Study. Cancer Res 1988;48:1653-7.

27. Crawford JR, MacDonald TJ, Packer RJ. Medulloblastoma in childhood: new biological advances. Lancet Neurol 2007;6:1073-85.

28. Canning CR, McCartney AC, Hungerford J. Medulloepithelioma (diktyoma). $\mathrm{Br} J$ Ophthalmol 1988;72:764-7.

29. Bignell GR, Canzian F, Shayeghi M, Stark M, Shugart YY, Biggs P, Mangion J, Hamoudi R, Rosenblatt J, Buu P, Sun S, Stoffer SS, Goldgar DE, Romeo G, Houlston RS Narod SA, Stratton MR, Foulkes WD. Familial nontoxic multinodular thyroid goiter locus maps to chromosome $14 q$ but does not account for familial nonmedullary thyroid cancer. Am J Hum Genet 1997;61:1123-30.

30. Griffin N, Devaraj A, Goldstraw P, Bush A, Nicholson AG, Padley S. CT and histopathological correlation of congenital cystic pulmonary lesions: a common pathogenesis? Clin Radiol 2008;63:995-1005.

31. Evans DG, Birch JM, Ramsden RT, Sharif S, Baser ME. Malignant transformation and new primary tumours after therapeutic radiation for benign disease: substantial risks in certain tumour prone syndromes. J Med Genet 2006:43:289-94. 